\title{
Subtalar Joint
}

National Cancer Institute

\section{Source}

National Cancer Institute. Subtalar Joint. NCI Thesaurus. Code C33653.

The plane synovial joint between the talus and calcaneus bones of the foot. 